\title{
Health is Wealth: A Corpus-driven Analysis of the Portrayal of Mental Health in Malaysian English Online Newspapers
}

\author{
Nor Fariza Mohd Nor ${ }^{a}$ \\ fariza@ukm.edu.my \\ Centre for Research in Language and Linguistics, \\ Faculty of Social Sciences and Humanities, \\ Universiti Kebangsaan Malaysia, Malaysia \\ Novelia Bernice Jeffree \\ p98604@siswa.ukm.edu.my \\ Centre for Research in Language and Linguistics, \\ Faculty of Social Sciences and Humanities, \\ Universiti Kebangsaan Malaysia, Malaysia \\ HilwaAbdullah@MohdNor ${ }^{b}$ \\ hilwa@ukm.edu.my \\ Centre for Research in Psychology and Human Well-being, \\ Faculty of Social Sciences and Humanities, \\ Universiti Kebangsaan Malaysia, Malaysia
}

\begin{abstract}
In view of the increase mental health cases in Malaysia, it is timely to examine how Malaysian newspapers portray mental health issues. A corpus-driven approach was employed to identify the adjective collocates for the node word mental health, determine the semantic grouping of the collocates and investigate the portrayal of mental health issues in two newspapers. A total of 585 news articles, from January 2020 to December 2020 were collected from the New Straits Times and The Star Online. The Antconc 3.5.8 software was used to generate the collocates and a discourse analysis approach was employed to examine how mental health issues were portrayed. 22 adjective collocates were identified in the New Straits Times, while 34 adjective collocates were extracted from The Star Online. 13 similar adjective collocates were found and based on the 13 adjective collocates, four semantic group of adjectives (emotive, miscellaneous, size and evaluative) were identified. A discourse analysis on the portrayal of mental health issues in the two newspapers seemed positive because the reports concentrated on the initiatives taken by the government and NGOs to handle mental health situations in Malaysia, with the aim of educating the public and raising their awareness about mental health. The present study has contributed significantly to research on mental health in the Asian context, since the review of literature revealed that research on mental health were mostly from the West. Furthermore, a corpus-driven approach which is systematic and rigorous allows for the comparison of the language across large datasets.
\end{abstract}

Keywords: mental health; corpus-driven; collocation analysis; news report; Malaysian English online newspapers

${ }^{a}$ Main author

${ }^{b}$ Corresponding author 


\section{INTRODUCTION}

Mental health problems affect people of all ages and can be caused by various factors such as family and financial issues (Mental Health Foundation, 2016). This issue has become prominent in the media in recent years (World Health Organisation, 2019). The attention given to mental health is heightened with the widespread outbreaks of Covid-19 since psychological factors are known to have a pivotal role on human in pandemic situations. Information, misinformation, fear, anxiety; to name a few seem to heighten concerns among the masses (Bao et al., 2020, Nor Fariza Mohd Nor \& Adlyn Zulcafli, 2020), resulting in mental health issues, such as anxiety and depression (Jung et al., 2020). Lazard et al. (2015) pointed out that past studies and experiences with large outbreaks of serious illnesses have indicated "potential for panic [which is] often a lot greater than the risk for the disease" (p. 857). The World Health Organization (WHO, 2004, p. 12) describes mental health as,

" a state of well-being in which the individual realizes his or her own abilities, can cope with the normal stresses of life, can work productively and fruitfully, and is able to make a contribution to his or her community".

The description implies that it is paramount to maintain mental health in order to function efficiently as an individual in the society. According to the Center for Disease Control, mental health reflects "our emotional, psychological, and social well-being." (Mc Lean, n.d. https://www.mcleanhospital.org/essential/yes-there-big-difference-between-mental-healthand-mental-illness).

In 2019, WHO reported that depression has affected more than 264 million people globally, which makes it one of the highest occurring mental problems, thus prompting the launch of a special initiative for Mental Health (2019-2023) :Universal Health Coverage for Mental Health, to ensure access to quality and affordable care for mental health conditions in 12 priority countries to 100 million more people (https://www.who.int/health-topics/mentalhealth) (WHO, 2019b).

As mental health problems increase in the society, reports on mental health appear every other day in the newspapers and in news broadcasts. The earliest report about inaccurate portrayal of mental health in the media was made by Nunnally (1957). In fact, the relationships between stigmatising representations of mental health and a negative perception of society towards individuals suffering from mental health have been documented by many (e.g. Pirkis et al., 2006; Pirkis \& Francis, 2012; Roth, 2004; Thorton \& Wahl, 2006). Klin and Lemish (2008) stated that the media provide inaccurate, exaggerated and misinformed descriptions about people who suffer from mental health problems. They are often described not only as peculiar, but also as different and dangerous. Similarly, Bowen and Lovell (2019) highlighted how media representations have often been disproportionately negative. The Mental Health Foundation (2015) asserted that media has always associated mental health patients and sufferers with violence; portraying them as dangerous individuals who are unable to live normal lives. Such portrayal will only enhance misconceptions and stigmatisation about mental health.

Tobin and Lyddy (2014) asserted that the accuracy of media representations about mental health is important in transmitting accurate information to the readers and influence public opinion. Therefore, if reports about mental health in the media are one-sided and are based on selective reporting, negative stereotypes and attitudes about mental health might be developed and reinforced. It is thus evident that representations of mental health in the media can shape the audiences' attitudes and create social representations on mental health in a certain manner (Ohlsson, 2018; Rhydderch et al., 2016). 
This study intends to examine the portrayal of mental health in the press. The impetus for this study came from the interest in the increased cases of mental health due to the Covid19 pandemic, globally and in Malaysia. A report by Our World in Data (2018, https://www.singlecare.com/blog/news/mental-health-statistics/) revealed that 970 million people worldwide suffer from mental health problems. In Malaysia, the Institute for Public Health (2019) reported that the prevalence of adults having depression is $2.3 \%$ and the figure is even higher for children between 5 to 15 years (i.e. $7.9 \%$ ).

Mental health cases in Malaysia have existed even before its independence with the first "lunatic asylum" in Malaya (the old Malaysia) being built at the end of 1890. The asylum was essential to curb mental illness among the sailors of the colonial navy (Chong et al., 2013). Over the years, different treatments and care are introduced based on the people's current needs (Lim, 2018). According to the Medical Developmental Vision Ministry of Health Malaysia (2011), outpatient care, inpatient care, psycho-education programme, rehabilitative services, hospital based outreach community psychiatric services (acute home care, assertive home care, family intervention programmes) are provided to improve mental health related cases in various hospitals around the country. To date, there is a total of 680 medical centres providing follow up and early detection programmes, and 27 health centres providing psychosocial rehabilitation programmes. Resident psychiatrists are also posted in all state hospitals and large district hospitals to accommodate the rising numbers of mental health cases. Mental health care places to provide treatments have also been established by the government and nongovernment organisations (NGOs) in Malaysia. For instance, the Malaysian Youth Mental Health Initiative (MINDA) and the Mental Illness Awareness and Support Association (MIASA) are NGOs which are set up to not only provide services and help to mental health patients, but also to spread awareness about mental health and to eradicate stigma on mental health in the society. The intensified attention given to mental health problems in Malaysia was evident with the allocation of RM24 million, announced during the Malaysian 2021 Budget speech, as an initiative to combat issues related to mental health in the society, particularly so due to the Covid-19 pandemic.

Despite the positive developments and initiatives to combat mental health problems in Malaysia, an article in The Star Online (2019) illustrated that stigmatisation towards mental health individuals still exist in the society as a result of negative portrayals in the mass media. Chen and Lawrie's (2017) study on newspapers' depictions of mental health in Malaysia found that people with mental disorders were portrayed more as the perpetrator of a crime rather than the victim, thus, accruing to the general public perception that mental problem is highly stigmatised in Malaysia (Ab. Razak, 2017).

To examine further how newspapers in Malaysia portray issues on mental health, the present study employed a corpus-driven approach to analyse the linguistic patterns of mental health-related articles. A review of literature on the portrayal of mental health in Malaysian newspapers revealed that only one study has been done to analyse how language is used in newspapers. However, the study investigated the state of mental illness (Razali et al., 2018), instead of mental health. Razali et al. (2018) used four mainstream Malay newspapers as data source and identified a negative tone about mental illness, such as associating it with crime and danger. The present study is therefore timely because it can contribute to the scant literature on mental health in Malaysia.

A review of literature on corpus studies in Malaysia revealed that noun is mainly chosen as the collocate under investigation. Azianura Hani Shaari et al. (2017) for instance conducted a corpus analysis on the lexical item jenayah (crime), Jamaluddin Aziz (2019) explored gender issues associated with women, Nor Fariza Mohd Nor et al. (2019) examined the representations around the word ekonomi (economy) and Norsimah Mat Awal et al. (2019) conducted a corpus- 
driven analysis on the noun water. The mentioned studies used the Malaysian Hansard corpus as the data source.

To achieve its overall aim, the present corpus-driven approach study used AntConc 3.5.8 software to generate collocates that occur with the node word mental health. The present study has chosen to analyse adjectives to determine how they describe the property in a semantic class as suggested by Bhat (1994), and to understand how speakers construct their acts of linguistic communication (Ferris, 1993). Ferris (1993) argued that an adjective is employed to supplement the linguistic communication process because noun alone is not enough to "identify the entity under consideration by the speaker" (p. 24). An understanding of the semantic class of adjective that collocates with the node word mental health can provide information about how mental health issues are linguistically portrayed. Furthermore, Bouillon and Viegas (1999) highlighted that although adjectives present an interesting polymorphic behaviour, they have not been studied much in traditional lexical semantics compared to the large amount of work devoted to verbs and nouns.

Adjectives constitute a challenging issue linguistically (Bouillon \& Viegas, 1999). From a syntactic viewpoint, they can be predicative or attributive, whilst from a semantic viewpoint, their sense can vary depending on the context in which they appear. For instance, when analysed syntactically, they can appear in different positions in a sentence, as modifier of the noun (a tragic book) or complement of a copular verb like be (this book is tragic). Semantically, adjectives, more than other categories, are able to take different meanings depending on their context (for example difficult in a difficult child, a difficult book, a difficult exam or fast in a fast car, a fast motorway, a fast procedure, etc.) (Kennedy, 2006).

To guide the present attempt at examining the portrayal of mental health issues in Malaysian newspapers, three research questions were formulated. Two online English newspapers were used as the data source. As such, the research questions are:

1. What are the adjective collocates for mental health in the two newspapers?

2. What are the semantic grouping of adjective collocates, based on Descriptor category in the two newspapers?

3. What can be discerned about the portrayal of mental health from its adjective collocates?

\section{REPRESENTATIONS OF MENTAL HEALTH IN THE MEDIA}

Past studies have shown that the mass media has been implicated in stigmatising the views held by the public towards people with mental health problems. As discussed earlier, representations of mental health in the media can have a significant effect on how the public perceive or form images of people who experience mental health problems (Dietrich et al., 2006; Nunnaly, 1957; Ohlsson, 2018; Razali et al., 2018; Rhydderch et al., 2016; Tobin \& Lydn, 2014). Slopen et al. (2007) reported that bad coverage given to mental health patients can generate adverse effects on public perceptions about people who suffer from mental health. Corrigan et al. (2005) also asserted that people with mental health problems are more likely to be presented or discussed in newspapers in the context of dangerousness or violence rather than treatment and recovery action.

At this point, it is evident how newspapers can act as a medium to spread ideas and concepts which can then potentially shape public opinion regarding certain issues (Assaf, 2020). Therefore, issues about mental health which are repetitively brought to attention in relation to violence will contribute to misconceptions and stigmatising meaning. Walter (2015) asserted that label-phrasing plays a role in reinforcing stigma towards mental health since 
language can create a framework for people's stereotypes which limit what a person can actually do.

Where corpus linguistics analysis approach is concerned, Bowen and Lovell's (2019) study which focused on schizophrenia patients in red-top tabloids of UK newspapers, however, reported how words associated with violence such as "murder" and "hammer" were widely and casually used in newspapers, thus, leading to negative views towards people diagnosed with schizophrenia. The negative representations of schizophrenia in newspapers strengthened the process of stigmatisation among schizophrenia sufferers in the society. The most recent study that employed corpus linguistics approach was by Price (2019), who explored the representation of mental health in the UK press. Although the results revealed that the domain of mental health is undergoing a semantic change, generally, reports that include symptoms of mental health are inaccurate or are reported in contexts that are too specific to serve the purpose of informing the public about mental health related illness.

Despite the negative coverage in the media on mental health patients, there have been attempts to publish reports with a more positive tone. News reports that discuss initiatives to support mental health patients, for instance, appeared less stigmatising in content. Throughout the 1990s in the UK, there was an increase in the media's attention on issues surrounding governmental community care legislation and the discharge of people from institutions (Anderson, 2003). According to Anderson et al. (2018), there was a positive trend between 2008 and 2016, with proportion of articles that were coded as danger to others, reduced from $21 \%$ to $17 \%$. Hannaford's (2017) longitudinal study of the UK press (1995-2014) using corpus linguistics analysis on the trends pertaining to coverage of mental health showed that there was a decrease in key stigmas in press coverage over the years that correlated with the decreases in negative public attitudes relating to these stigmas. This positive direction appears to be largely motivated by increases in news reports that provide readers with a better understanding of mental health (Goulden et al., 2011).

This review has shown that individuals suffering from mental health are frequently portrayed as dangerous and violent in the media, resulting in stigmatising attitudes towards this vulnerable group of people. Descriptions of mental health issues in the newspapers therefore need to be sensitively monitored as they not only affect individuals suffering from mental health problems, but they can also continue to fuel stigma and fear towards mental health patients in the society (Woo, 2018). Additionally, journalists should always be careful with word choice and include more news about positive mental health treatments when reporting about mental health issues (Whitley, 2018).

\section{METHODOLOGY}

As mentioned, a corpus-driven approach was employed in this study. According to Storjohann (2005), the corpus-driven approach is "a methodology where the corpus acts as an empirical basis in which researcher extracts data and analyse patterns without any expectations or assumptions." (p. 5). It is therefore, the most suitable approach employed as the objectives are to identify adjective collocates for mental health and to discern the portrayal of mental health from the adjective collocates in the two English newspapers. Quantitative and qualitative methods were employed to analyse the corpus. The quantitative analysis involved the use of AntConc 3.5.8 software to generate the collocates. Then a manual analysis was done to categorise the adjectives into the appropriate semantic grouping of adjectives based on Biber et al. (1999). For the qualitative analysis, a discourse analysis was conducted to answer the third research question, which enabled the researchers to obtain insight and understanding about the discourse surrounding the news on mental health issues. 


\section{THE CORPUS}

The Corpus of Malaysian Online News Articles on Mental Health has been developed for this study. The corpus comprised a collection of news articles from two local news portals: The New Straits Times (https://www.nst.com.my) and The Star Online (https://www.thestar.com.my). According to the Reuters Institute Digital News Report 2020, the New Straits Times and The Star Online are local online English news portals that have among the top readerships in Malaysia (Newman et al., 2020). Both provide easy accessibility in terms of search functions that are free of charge in order to collect data that are relevant to the study. In addition, both are among the most trusted news portals in reporting news, thus, another reason why these two newspapers were selected as the source of data for the present study.

The corpus comprises raw data where authentic, written electronic texts were collected. A total of 248 news articles were collected from the New Straits Times and 337 articles were gathered from The Star Online, which made up a total of 585 news articles. The corpus of this study has a total of 23,856-word types, comprising 320,509-word tokens which involved 247 and 336 news articles from the New Straits Times and The Star Online respectively. The word "mental health" was used as the keyword in the search term to collect related articles. News articles dated $1^{\text {st }}$ January 2020 to $31^{\text {st }}$ December 2020 were selected as the data for this study for two main reasons. Firstly, there was an increase of mental health problems among Malaysians as reported by the National Health and Morbidity Survey 2019 released by the Institute for Public Health (2019), which revealed that mental health problems among Malaysians have increased from $10.7 \%$ in 1996 to $29.2 \%$ in 2015 . 424,000 children were found to have mental health problems while $2.3 \%$ Malaysian adults were found to have depression. Secondly, the Ministry of Health's Psychosocial Helpline has received more than 35,000 phone calls since March 2020 until October 2020 during the Covid-19 pandemic. Therefore, the time frame chosen for the data collection is appropriate and timely.

\section{DATA PROCESSING}

The collected news articles were filtered by emitting irrelevant and repeated news articles. The filtered news articles were then converted into text (txt.) format before being inserted into Antconc 3.5.8 software. Antconc was employed to analyse the corpus of the online news articles on mental health, in order to generate the collocates. Mutual Information (henceforth MI) score to quantify the collocational strength between two words was computed using the calculation formulated by Gaussier, Langé and Maunier which was described in Oakes (1998: p. 174). The MI takes the likelihood of the collocate with the node word based on the corpus size (word token). The MI score gives researchers information on the collocate likelihood with the node word. The collocates were identified by taking into account the span of five words on the left and the right of the node word. After the collocates were identified, stopwords like "is", "are" and other stopwords were discarded before the collocates they were classified according to their word forms: noun, verb, adjective, etc.

Only adjective collocates with a minimum frequency of 3 and a minimum MI score of 3 were analysed in this study. According to Xiao and McEnery (2006), MI score of 3 and above can be considered as the collocates of the node word. The analysis in the present study involved determining the types of adjective collocates based on Biber's et al. (1999) adjective category. The adjective category proposed by Biber et al. is categorised into two major groups known as Classifiers and Descriptors. Descriptor comprises of size, colour, time, emotive and miscellaneous descriptive (Table 1). Biber et al. (1999), however, did not elaborate on the miscellaneous sub-category. Bieber et al. (ibid) further mentioned that the sub-category of adjectives for Descriptor express a level of degree of the characteristics expressed. Classifiers, 
on the other hand, refers to non-gradable adjectives. The identified adjective collocates generated by AntConc 3.5.8 software produced the list of adjective collocates to answer the first research question. The adjective collocates were then classified according to Biber et al.'s (1999) adjective categories. The analysis addressed the second research question. A discourse analysis of excerpts on mental health issues from the two newspapers was conducted to answer the third research question.

The present study focused only on semantic analysis for Descriptor because the objectives of this study are to determine the categories of semantic grouping for adjectives and to find out what can be discerned about the portrayal of mental health in the two newspapers from the adjective collocates. The semantic grouping for Classifier examines the traits of adjectives, whether they are negative or positive, which is not the focus of the present study.

TABLE 1. Sub-Categories for Descriptor

\begin{tabular}{llll}
\hline No & Sub-Categories & Description & Examples \\
\hline 1 & Colour & Denoting colour and brightness & $\begin{array}{l}\text { Black, white, dark, bright, blue, } \\
\text { brown, green, grey, red }\end{array}$ \\
2 & Size, quantity & Denoting size, weight and extent & $\begin{array}{l}\text { Big, deep, heavy, huge, log, large, } \\
\text { little, short, small, thin, wide }\end{array}$ \\
3 & Time & $\begin{array}{l}\text { Denoting chronology, age, } \\
\text { Annual, daily, late, new, old, recent, } \\
\text { frequency }\end{array}$ \\
4 & Evaluative/emotion & $\begin{array}{l}\text { Denoting judgement, affect, } \\
\text { emphasis }\end{array}$ & $\begin{array}{l}\text { Bad, beautiful, fine, best, good, great, } \\
\text { lovely, nice, poor } \\
\text { Appropriate, cold, complex, empty, } \\
\text { free, hard, hot, open, positive, } \\
\text { practical, private, serious, storage }\end{array}$ \\
\hline
\end{tabular}

\section{RESULTS}

In this section, results based on the corpus analysis that revealed the adjective collocates for mental health in the New Straits Times and The Star Online will be presented first, followed by results based on the semantic grouping of adjectives from the two newspapers. A discourse analysis of excerpts from both newspapers will then be presented to examine how mental health issues from the adjective collocates were portrayed in the two newspapers.

\section{COLLOCATION ANALYSIS}

The definition of collocation adopted in the present study is the above-chance frequent cooccurrence of two words within a pre-determined span, usually five words on either side of the word under investigation (the node) (see Sinclair, 1991). The statistical calculation of collocation is based on three measures: the frequency of the node, the frequency of the collocates, and the frequency of the collocation.

As demonstrated in Table 2, results from the corpus analysis showed that 22 adjectives collocates associated with the node word mental health were identified in the New Straits Times. The adjective collocate health has the highest MI score, which is at 7.13213, while the adjective important has the lowest MI score (3.21371). The adjective collocate health also obtained the highest raw frequency of 357 . The lowest raw frequency is 3 , and the adjective collocates are psychological, protective, international, healthcare, governmental and confined. 
TABLE 2. Adjective Collocates in the New Straits Times

\begin{tabular}{cccccc}
\hline N & Frequency & $\begin{array}{c}\text { Frequency } \\
\text { left }\end{array}$ & $\begin{array}{c}\text { Frequency } \\
\text { right }\end{array}$ & MI SCORE & COLLOCATE \\
\hline 1 & 357 & 17 & 340 & 7.13213 & health \\
20 & 19 & 5 & 14 & 4.89811 & support \\
23 & 17 & 16 & 1 & 4.99873 & physical \\
26 & 16 & 16 & 0 & 4.53404 & world \\
50 & 10 & 3 & 7 & 6.89639 & psychosocial \\
51 & 10 & 9 & 1 & 4.39003 & good \\
54 & 8 & 3 & 5 & 3.25253 & well \\
72 & 6 & 5 & 1 & 5.00414 & related \\
73 & 6 & 4 & 2 & 3.43894 & public \\
79 & 6 & 5 & 1 & 4.42903 & emotional \\
100 & 5 & 4 & 1 & 3.22653 & malaysian \\
101 & 5 & 5 & 0 & 4.42508 & increase \\
122 & 4 & 3 & 1 & 4.44893 & personal \\
129 & 4 & 4 & 0 & 3.51033 & long \\
134 & 4 & 2 & 2 & 3.21371 & important \\
136 & 4 & 2 & 2 & 5.57446 & greater \\
156 & 3 & 2 & 1 & 3.89093 & psychological \\
159 & 3 & 2 & 1 & 6.44893 & protective \\
178 & 3 & 2 & 1 & 3.57446 & international \\
186 & 3 & 0 & 3 & 3.64157 & healthcare \\
189 & 3 & 3 & 0 & 5.09529 & governmental \\
200 & 3 & 0 & 3 & 5.71196 & confined \\
\hline
\end{tabular}

Results from the corpus analysis in The Star Online (see Table 3) showed that 34 adjectives collocates associated with mental health were present. Similar to the result for the New Straits Times, the adjective collocate health has the highest MI score (6.91192). The adjective collocate higher obtained the lowest MI score (3.09018). The adjective collocate health also has the highest raw frequency that is at 640 . The lowest raw frequency is 3 , and the six adjectives collocates are abled, immediate, encouraging, proper, clinical, professional, domestic and higher.

TABLE 3. Adjective Collocates in The Star Online

\begin{tabular}{cccccc}
\hline N & FREQ & FREQ L & FREQ R & MI SCORE & COLLOCATE \\
\hline 1 & 640 & 22 & 618 & 6.91192 & health \\
3 & 38 & 10 & 28 & 4.95478 & support \\
5 & 34 & 33 & 1 & 5.03587 & world \\
8 & 29 & 27 & 2 & 5.44936 & Malaysian \\
17 & 16 & 14 & 2 & 5.464 & international \\
18 & 16 & 7 & 9 & 3.44884 & well \\
22 & 14 & 0 & 14 & 6.4211 & psychosocial \\
29 & 12 & 9 & 3 & 4.77244 & financial
\end{tabular}




\begin{tabular}{cccccc}
30 & 11 & 9 & 2 & 3.80639 & physical \\
44 & 9 & 6 & 3 & 3.68564 & important \\
45 & 9 & 5 & 4 & 3.36582 & online \\
68 & 6 & 5 & 1 & 4.73928 & increased \\
71 & 6 & 5 & 1 & 4.44382 & provided \\
87 & 5 & 4 & 1 & 4.80639 & serious \\
91 & 5 & 5 & 0 & 4.41211 & poor \\
97 & 5 & 3 & 2 & 3.76575 & psychological \\
101 & 5 & 3 & 2 & 3.36582 & future \\
104 & 5 & 3 & 2 & 3.06531 & emotional \\
115 & 4 & 3 & 1 & 5.80639 & proactive \\
122 & 4 & 2 & 2 & 5.02878 & greater \\
124 & 4 & 2 & 2 & 4.96989 & primary \\
135 & 4 & 3 & 1 & 4.09018 & negative \\
136 & 4 & 3 & 1 & 4.05916 & former \\
142 & 4 & 4 & 0 & 3.63647 & positive \\
143 & 4 & 2 & 2 & 3.61375 & healthy \\
149 & 4 & 3 & 1 & 3.18748 & long \\
160 & $\mathbf{3}$ & 0 & 3 & 6.39135 & abled \\
166 & $\mathbf{3}$ & 3 & 0 & 5.49827 & immediate \\
171 & $\mathbf{3}$ & 1 & 2 & 5.29182 & encouraging \\
177 & $\mathbf{3}$ & 1 & 2 & 4.95078 & proper \\
200 & $\mathbf{3}$ & 1 & 2 & 4.19871 & clinical \\
201 & $\mathbf{3}$ & 1 & 2 & 4.15431 & professional \\
208 & $\mathbf{3}$ & 1 & 2 & 3.80639 & domestic \\
225 & $\mathbf{3}$ & 1 & 2 & 3.09018 & higher \\
\hline & & & & &
\end{tabular}

\section{SEMANTIC GROUPING OF ADJECTIVES}

Results obtained from the analysis of adjective collocates based on the semantic grouping of adjectives for Descriptor (Biber et al., 1999) in the New Straits Times is presented in Table 4. The highest sub-category, as evident in the table, is miscellaneous with nine adjectives (physical, related, public, Malaysian, personal, international, healthcare, governmental, confined), followed by six adjectives in the emotive sub-category (support, psychosocial, good, well, emotional, psychological). Next is the evaluative sub-category with two adjectives (health, important), three adjectives are in the sub-category of size (world, long, greater) and the final category is the quantity sub-category, with one adjective only (increase).

TABLE 4. Semantic Grouping of Adjectives: Sub-Categories for Descriptor

\begin{tabular}{ccc}
\hline No & Adjective Collocates & Sub-Categories \\
\hline 1 & health & evaluative \\
2 & support & emotive \\
3 & physical & miscellaneous \\
4 & world & miscellaneous \\
5 & psychosocial & emotive \\
6 & good & emotive \\
\hline
\end{tabular}




\begin{tabular}{ccc}
\hline 7 & well & emotive \\
8 & related & miscellaneous \\
9 & public & miscellaneous \\
10 & emotional & emotive \\
11 & Malaysian & miscellaneous \\
12 & increase & quantity \\
13 & personal & miscellaneous \\
14 & long & size \\
15 & important & evaluative \\
16 & greater & size \\
17 & psychological & emotive \\
18 & protective & evaluative \\
19 & international & miscellaneous \\
20 & healthcare & miscellaneous \\
21 & governmental & miscellaneous \\
22 & confined & miscellaneous \\
\hline
\end{tabular}

The concordance analysis revealed that adjectives which are in the miscellaneous category were employed to describe the government's effort in managing mental health problems and issues in Malaysia. A similar observation was also found for emotive and evaluative categories. Since emotive and evaluative are commonly used to persuade readers to agree and believe in any information, the news reports mainly focussed on the importance of taking care of one's mental health, explanation of mental health, how and where to seek help if an individual is suffering from mental health, and the government's initiatives in handling mental health issues in Malaysia.

Table 5 presents the results for semantic grouping of adjectives for Descriptor in The Star Online, based on Biber et al. (1999). The results indicate that the highest sub-category is miscellaneous with 12 adjectives (Malaysian, international, financial, physical, online, provided, healthy, abled, proper, clinical, professional, and domestic). The second highest category of semantic grouping is the evaluative sub-category (health, well, important, serious, poor, proactive, primary, negative, and positive). There are five adjectives in the emotive subcategory (support, psychosocial, psychological, emotional, and encouraging), four adjectives are in the size sub-category (world, greater, long, and higher), three adjectives are in the time sub-category (future, former, and immediate) and one adjective is in the quantity sub-category (increased). The adjectives in the miscellaneous category were frequently used in The Star Online to promote the initiatives taken by the government in managing mental health problems, whilst the evaluative and emotive adjectives were used to describe the state of an individual's mental health and the problems associated with it.

TABLE 5. Semantic Grouping of Adjectives: Sub-Categories for Descriptor

\begin{tabular}{ccc}
\hline No & Adjective collocates & Sub-categories \\
\hline 1 & health & evaluative \\
3 & support & emotive \\
5 & world & size \\
8 & Malaysian & miscellaneous \\
17 & international & miscellaneous \\
18 & well & evaluative \\
22 & psychosocial & emotive \\
29 & financial & miscellaneous \\
30 & physical & miscellaneous \\
44 & important & evaluative \\
45 & online & miscellaneous \\
68 & increased & quantity \\
71 & provided & miscellaneous \\
\hline
\end{tabular}




\begin{tabular}{ccc}
\hline 87 & serious & evaluative \\
91 & poor & evaluative \\
97 & psychological & emotive \\
101 & future & time \\
104 & emotional & emotive \\
115 & proactive & evaluative \\
122 & greater & size \\
124 & primary & evaluative \\
135 & negative & evaluative \\
136 & former & time \\
142 & positive & evaluative \\
143 & healthy & miscellaneous \\
149 & long & size \\
160 & abled & miscellaneous \\
166 & immediate & time \\
171 & encouraging & emotive \\
177 & proper & miscellaneous \\
200 & clinical & miscellaneous \\
201 & professional & miscellaneous \\
208 & domestic & miscellaneous \\
225 & higher & size \\
& & \\
\hline
\end{tabular}

Since evaluative and emotive adjectives are usually used to persuade readers to believe in the information, it is expected that these two sub-categories are associated with the effect and consequences of mental health problems. Although there was only one adjective in the quantity sub-category, this adjective (increase) referred to the rising cases of the mental health situation in Malaysia. Reference to the texts demonstrated that mental health cases in Malaysia are consistently increasing especially during the Covid-19 pandemic.

\section{NORMALISED FREQUENCY FOR ADJECTIVE COLLOCATES}

Table 6 shows the result for normalised frequencies and MI score for adjective collocates in the New Straits Times and The Star Online. Thirteen similar adjectives frequently occurred in the two newspapers. Adjective health has the highest normalised frequency (36.90419901), while the lowest is the adjective international with normalised frequency of 0.922604975 . Although adjective health has higher normalised frequency in The Star Online, the MI score for adjective health is higher in the New Straits Times (7.13213) than in The Star Online (6.91192). The reason for this is that normalised frequency is a unit of measurement of frequency equivalent to the corpus, while MI score is a measure of the strength of association between two words. Therefore, although the normalised frequency for a particular adjective is higher in the other newspaper, it does not necessarily mean that the MI score will also be high.

TABLE 6. Similar Adjective Collocates of The New Straits Times (NST) and The Star Online (TS)

\begin{tabular}{|c|c|c|c|}
\hline ADJECTIVE COLLOCATES & & NST & TS \\
\hline \multirow{2}{*}{ health } & $\begin{array}{l}\text { Normalised } \\
\text { Frequency }\end{array}$ & $2,391.318909505$ & $3,690.419900589$ \\
\hline & MI score & 7.13213 & 6.91192 \\
\hline \multirow{2}{*}{ support } & $\begin{array}{l}\text { Normalised } \\
\text { Frequency }\end{array}$ & 127.269073615 & 219.118681597 \\
\hline & MI score & 4.89811 & 4.95478 \\
\hline physical & $\begin{array}{l}\text { Normalised } \\
\text { Frequency }\end{array}$ & 113.872329 & 63.429092041 \\
\hline
\end{tabular}




\begin{tabular}{|c|c|c|c|}
\hline & MI score & 5.00241 & 3.80639 \\
\hline \multirow{2}{*}{ world } & $\begin{array}{l}\text { Normalised } \\
\text { Frequency }\end{array}$ & 107.1739567 & 190.287276124 \\
\hline & MI score & 4.53404 & 5.03587 \\
\hline \multirow{2}{*}{ psychosocial } & $\begin{array}{l}\text { Normalised } \\
\text { Frequency }\end{array}$ & 66.983723 & 80.7279353 \\
\hline & MI score & 6.89639 & 6.4211 \\
\hline \multirow{2}{*}{ well } & $\begin{array}{l}\text { Normalised } \\
\text { Frequency }\end{array}$ & 53.5869784 & 92.2604975 \\
\hline & MI score & 3.25253 & 3.44884 \\
\hline \multirow{2}{*}{ emotional } & $\begin{array}{l}\text { Normalised } \\
\text { Frequency }\end{array}$ & 40.1902338 & 28.8314055 \\
\hline & MI score & 4.42903 & 3.06531 \\
\hline & $\begin{array}{l}\text { Normalised } \\
\text { Frequency }\end{array}$ & 33.491861478 & 167.2221517 \\
\hline Malaysian & MI score & 3.22653 & 5.44936 \\
\hline \multirow[t]{2}{*}{ long } & $\begin{array}{l}\text { Normalised } \\
\text { Frequency }\end{array}$ & 26.7934892 & 23.0651244 \\
\hline & MI score & 3.51033 & 3.18748 \\
\hline \multirow[t]{2}{*}{ important } & $\begin{array}{l}\text { Normalised } \\
\text { Frequency }\end{array}$ & 26.7934892 & 51.8965299 \\
\hline & MI score & 3.21371 & 3.68564 \\
\hline \multirow{2}{*}{ greater } & $\begin{array}{l}\text { Normalised } \\
\text { Frequency }\end{array}$ & 26.7934892 & 23.0651244 \\
\hline & MI score & 5.57446 & 5.02878 \\
\hline \multirow{2}{*}{ psychological } & $\begin{array}{l}\text { Normalised } \\
\text { Frequency }\end{array}$ & 20.0951169 & 28.8314055 \\
\hline & MI score & 3.89093 & 3.76575 \\
\hline \multirow[t]{2}{*}{ international } & $\begin{array}{l}\text { Normalised } \\
\text { Frequency }\end{array}$ & 20.0951169 & 92.2604975 \\
\hline & MI score & 3.57446 & 5.464 \\
\hline
\end{tabular}

The analysis based on the semantic grouping of adjectives (Biber et al., 1999) revealed that the highest category of semantic grouping of adjectives in the two newspapers is the emotive category; support, psychosocial, well, emotional and psychological. This is followed by the semantic grouping of adjective for the miscellaneous category (physical, Malaysian and international and world). Next is the size category (long and greater). Finally, is the semantic grouping of adjectives for evaluative with two adjective collocates (health and important).

\section{DISCOURSE ANALYSIS}

The qualitative analysis involved a discourse analysis approach in which excerpts of a few of the adjective collocates in Table 6 were extracted from the concordance list to illustrate the usage of the adjective collocates in the news reports.

\section{SEMANTIC GROUPING OF ADJECTIVES FOR EMOTIVE}

The highest category of semantic grouping of adjectives (see Table 6), as mentioned, is the emotive category and there are five adjectives in this semantic category. The two adjectives that will be described and discussed are support and psychosocial. 
The adjective collocate support has higher normalised frequency and higher MI score in The Star (219.118681597) than in the New Straits Times (127.269073615). Figure 1 depicts the concordance list for the adjective collocate support from The Star Online.
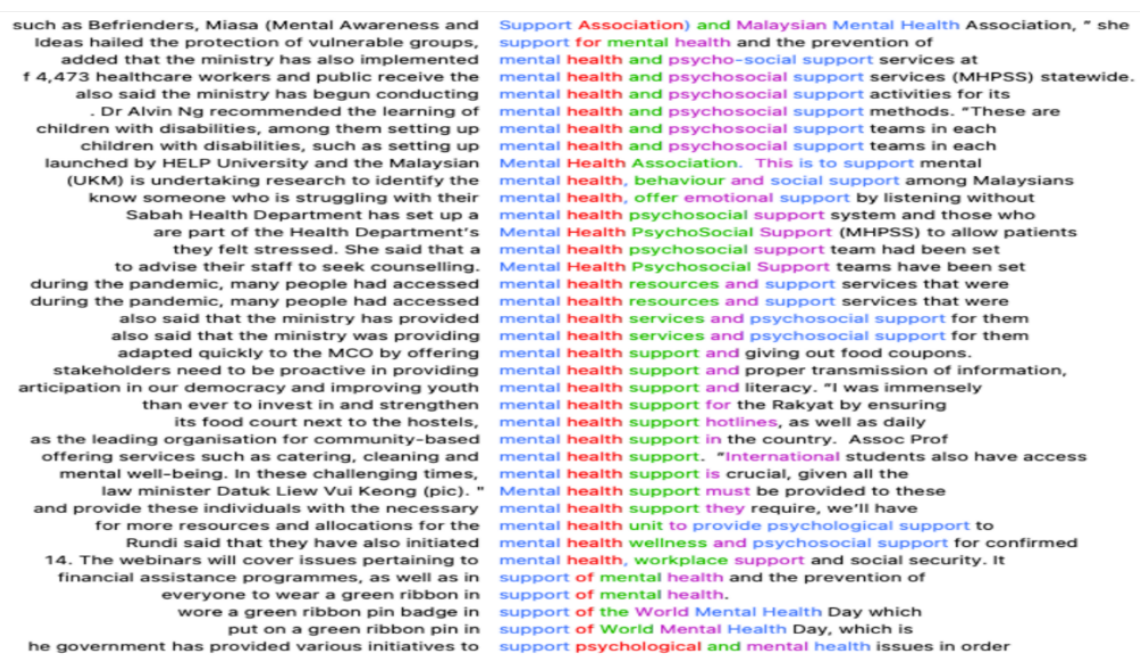

FIGURE 1. Concordance list for adjective collocate support in The Star Online

Excerpts in Examples 1 and 2 from The Star Online illustrated the contexts in which adjective support was used. Since it has emotive characteristics, the adjective referred to the psychosocial support activities provided by the Ministry of Health, specifically during the MCO and the Covid-19 crisis.

Example 1: Dr Noor Hisham also said the ministry has begun conducting mental health and psychosocial support activities for its healthcare workers at the hospital.

Example 2: The Health Ministry received more than 43,000 calls via its psychosocial support hotline since the movement control order was introduced on March 18 right up to Dec 1, involving various issues due to emotional stress.

\section{CONCORDANCE LIST AND EXCERTS FOR THE ADJECTIVE COLLOCATE SUPPORT IN THE NEW STRAITS TIMES}

Figure 2 shows the concordance list with the adjective collocate support from the New Straits Times. The context for the usage of this adjective collocate is similar to The Star Online, whereby it was used to describe the support groups and services set up by the Malaysian government during the Covid-19 pandemic, as shown in the excerpts in Example 3 and 4. 


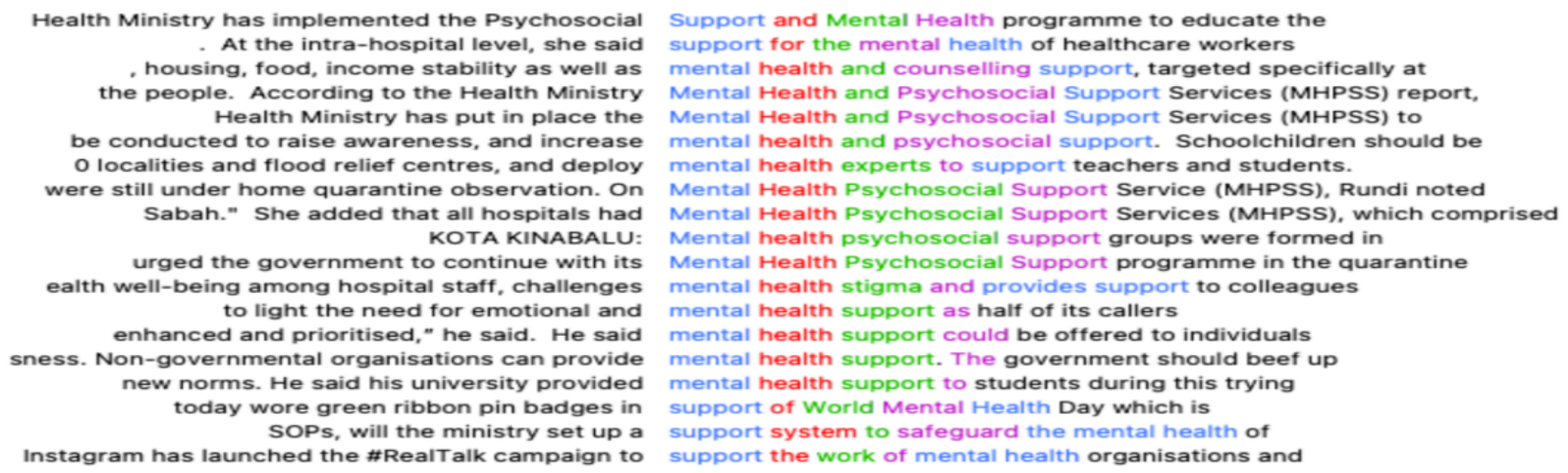

FIGURE 2. Concordance list for adjective collocate support in The New Straits Times

Example 3: Mental health psychosocial support groups were formed in every Sabah district since early this year to assist those affected by Covid-19, including healthcare workers, said state Health Director Datuk Dr Christina Rundi.

Example 4: The Health Ministry has put in place the Mental Health and Psychosocial Support Services (MHPSS) to help medical frontliners who are suffering from extreme mental and physical fatigue during the Covid-19 pandemic.

\section{CONCORDANCE LIST AND EXCERPTS FOR ADJECTIVE COLLOCATE PSYCHOSOCIAL IN THE STAR ONLINE}

The adjective collocate psychosocial obtained normalised frequency of 80.7279353 and MI score of 6.4211, in The Star Online and normalised frequency of 66.983723 and MI score of 6.89639 in the New Straits Times. The adjective obtained higher normalised frequency in The Star Online and higher MI score in the New Straits Times. Figure 3 displays the concordance list.

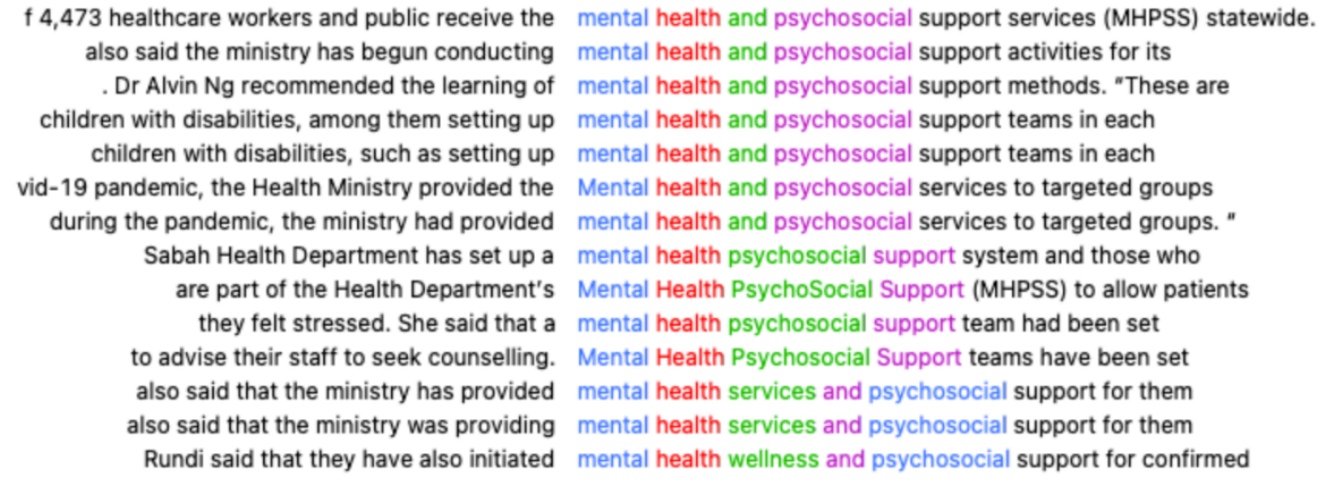

FIGURE 3. Concordance list for adjective collocate psychosocial in The Star Online

It is evident from Examples 5 and 6 that psychosocial support is especially important for individuals who are struggling with mental health problems.

Example 5: Dr Alvin Ng recommended the learning of mental health and psychosocial support methods. "These are useful in helping yourself as well as others who may need more emotional support. It can be very therapeutic for you when you are able to help people," he said, adding that acknowledging your own vulnerabilities and seeking help for them are a good start to managing emotions in a healthy manner and increasing the frequency of experiencing positive, pleasant emotions. 
Example 6: She said the department had also seen a total of 4,473 healthcare workers and public receive the mental health and psychosocial support services (MHPSS) statewide.

In Example 5, Dr Alvin $\mathrm{Ng}$ recommended that those affected to get psychosocial support, which can assist in managing emotions. While in Example 6, the government has set up psychosocial support services in health centres to assist healthcare workers and the public who are suffering from mental health problems, due to rising cases of mental health problems during the Covid-19 pandemic.

\section{CONCORDANCE LIST AND EXCERPTS FOR ADJECTIVE COLLOCATE PSYCHOSOCIAL IN THE NEW STRAITS TIMES}

Figure 4 displays the concordance list for the adjective collocate psychosocial from the New Straits Times.

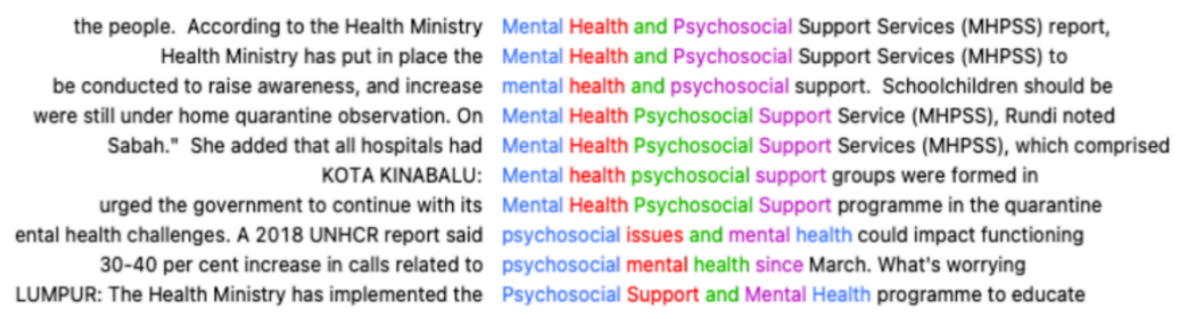

FIGURE 4. Concordance list for adjective collocate psychosocial in the New Straits Times

Examples 7 and 8 are excerpts taken from the New Straits Times.

Example 7: Wong adds that statistics show that child helplines worldwide have seen a 30-40 per cent increase in calls related to psychosocial mental health since March.

Example 8: The Health Ministry has put in place the Mental Health and Psychosocial Support Services (MHPSS) to help medical frontliners who are suffering from extreme mental and physical fatigue during the Covid-19 pandemic.

Due to the Covid-19 pandemic, people do not see each other, resulting in emotional disturbance since there is less psychosocial support from close family members and friends. The Mental Health and Psychosocial Support Services (MHPSS) has been set up by the government (Example 8) to help those suffering mentally and physically, including the frontliners. Even children suffered from the increasing number of mental health problems as demonstrated in Example 7.

\section{SEMANTIC GROUPING OF ADJECTIVES FOR MISCELLANEOUS}

Four adjectives collocates were categorised in the semantic grouping of adjectives for miscellaneous; physical, world, international and malaysian (see Table 6). Adjective collocates physical and world have been chosen to demonstrate the portrayal of the two adjective collocates in the New Straits Times and The Star Online.

\section{CONCORDANCE LIST AND ADJECTIVE COLLOCATE FOR PHYSICAL IN THE NEW STRAITS TIMES}

The adjective collocate physical (see Table 6) has higher normalised frequency in the New Straits Times (113.872329) and higher MI score (5.00241) than in The Star Online (normalised frequency of 63.429092 and MI score of 3.80639). 
The concordance list (see Figure 5) shows that the adjective collocate physical in the New Straits Times is mainly associated with physical health. Both physical and mental health are health concerns that affect an individual's physical and mental health.

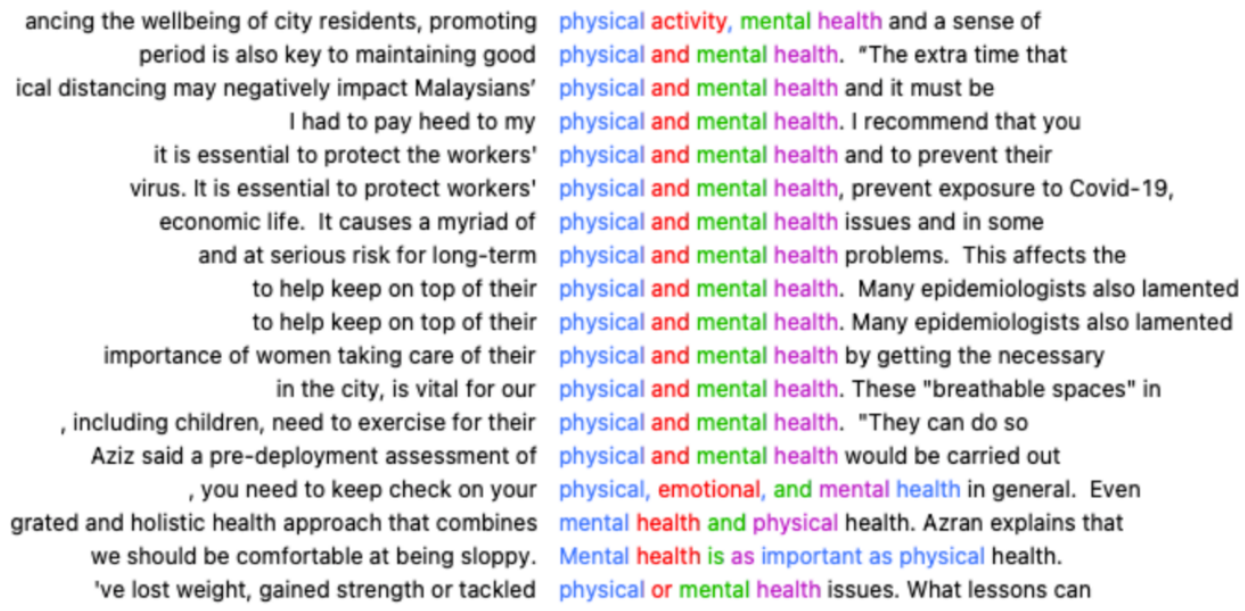

FIGURE 5. Concordance list for adjective collocate physical in the New Straits Times

Examples 9 and 10 were extracted from the concordance to illustrate how the adjective collocate physical was used in the news report.

Example 9: Exercise aside, being deliberate about daily routines and habits during the MCO period is also key to maintaining good physical and mental health.

Example 10: Extended physical distancing may negatively impact Malaysians' physical and mental health and it must be addressed.

Physical and mental health are both crucial in fighting against Covid-19. The Movement Control Order (MCO), nevertheless, has restricted travelling and social activities including recreational activities. The government (Examples 9 and 10), thus, encourages everyone to do some physical activities at home in order to maintain good physical and mental health.

\section{CONCORDANCE LIST AND EXCERPTS FOR ADJECTIVE COLLOCATE PHYSICAL IN THE STAR ONLINE}

As depicted in the concordance list in Figure 6, the adjective physical was mainly employed in The Star Online to emphasise the importance of physical and mental health, which was similar to the content in the New Straits Times.

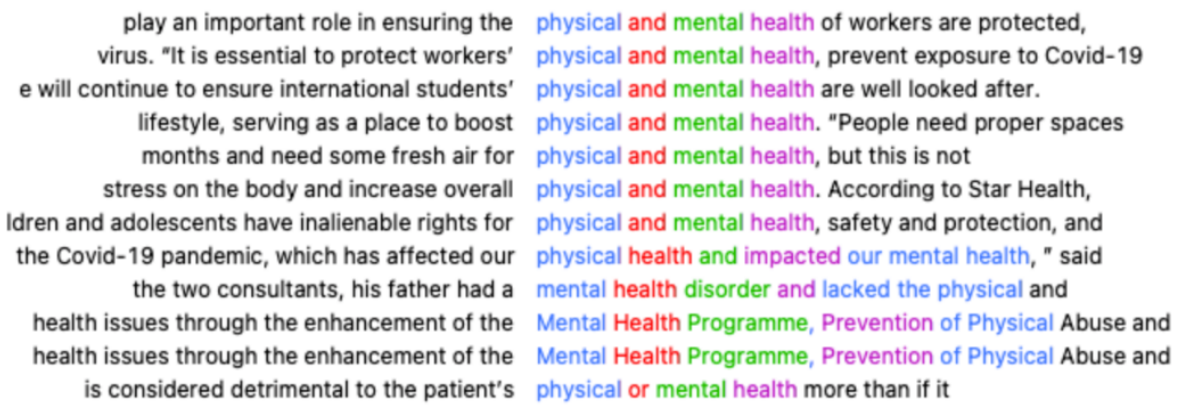

play an important role in ensuring the physical and mental health of workers are protected,

FIGURE 6. Concordance list for adjective collocate physical in The Star Online 
Examples 11 and 12 demonstrated how the adjective was used in context.

Example 11: Our National Health Service has taken care of people from around the world and we will continue to ensure international students' physical and mental health are well looked after.

Example 12: A regular practice of breathing exercises (pranayama) can help strengthen your lungs. Pranayama can also decrease the effects of stress on the body and increase overall physical and mental health.

In Example 11, the Malaysian National Health Service made a pledge that international students' physical and mental health will be looked after, while suggestion on how to increase overall physical and mental health was given in Example 12. This suggests that physical health is closely associated with mental health.

\section{CONCORDANCE LIST AND EXCERPTS FOR THE ADJECTIVE COLLOCATE WORLD IN THE STAR ONLINE}

The adjective collocate world (see Table 6) has higher normalised frequency in The Star Online (190.2872761) and higher MI score (5.03587) than in the New Straits Times (normalised frequency of 107.1739567 and MI score of 4.53404). The concordance list seen in Figure 7 shows that world in The Star Online is mainly associated with global health organisations that were involved in the World Mental Health Day 2020.

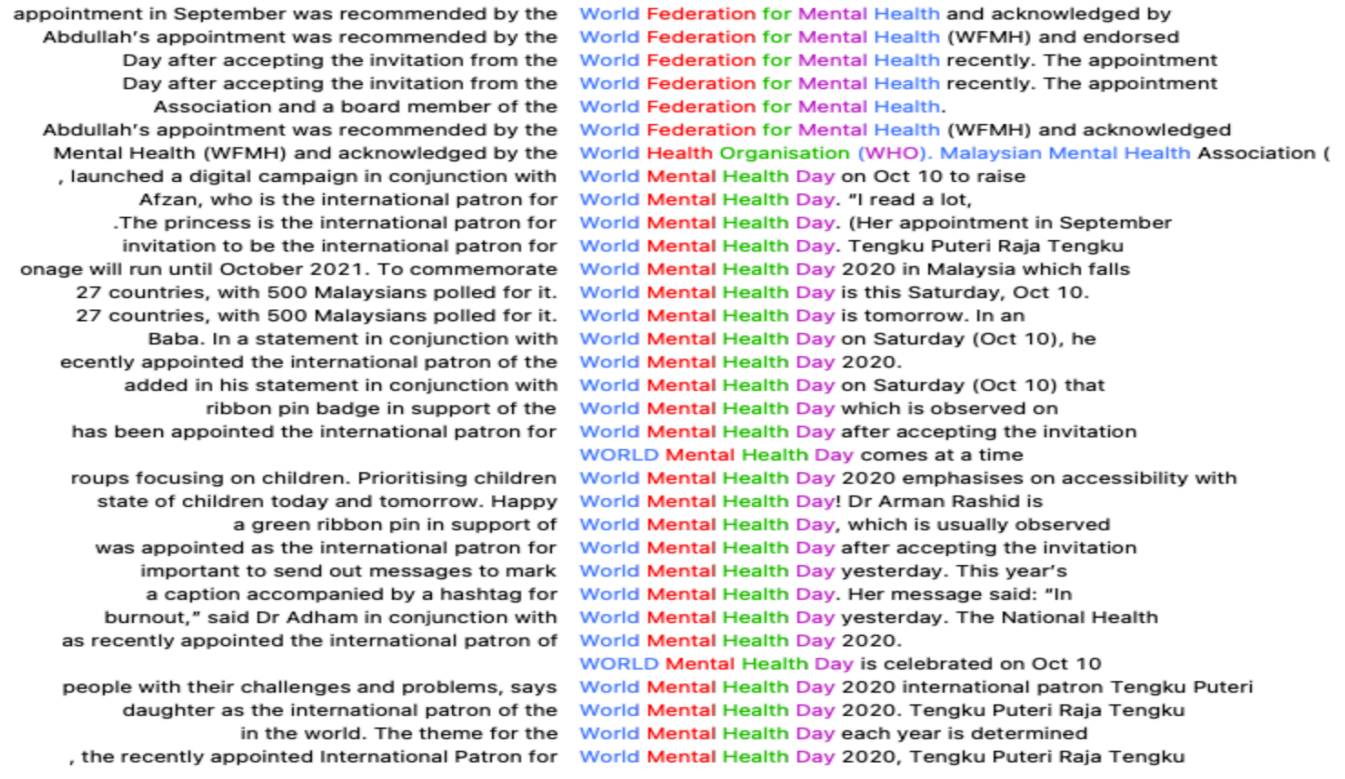

FIGURE 7. Concordance list for adjective collocate world in The Star Online

Example 13: Tengku Puteri Raja Tengku Puteri Iman Afzan Al Sultan Abdullah's appointment was recommended by the World Federation for Mental Health (WFMH) and acknowledged by the World Health Organisation (WHO). Malaysian Mental Health Association (MMHA) president Datuk Dr Andrew Mohanraj said the appointment was a great honour for the nation.

Example 14: Lee added in his statement in conjunction with World Mental Health Day on Saturday (Oct 10) that the National Health Morbidity Survey (NHMS) 2019 found that close to half a million of Malaysians are reported to have symptoms of depression. 
The appointment of Tengku Puteri Raja Tengku Puteri Iman Afzan in Example 13 as the international patron of the World Mental Health Day is hoped to raise awareness among Malaysians concerning mental health problem in a positive light. Furthermore, the report by the NHMS in Example 14 which indicated that close to half a million of Malaysians were reported to have symptoms of depression definitely raised concern about the state of mental health among Malaysians.

Based on the concordance list in the New Straits Times (Figure 8), the adjective collocate world was employed for the same purpose in the New Straits Times. The adjective was used mainly to refer to renowned health organisations and to report about the World Mental Health Day, as depicted in the Examples 15 and 16.

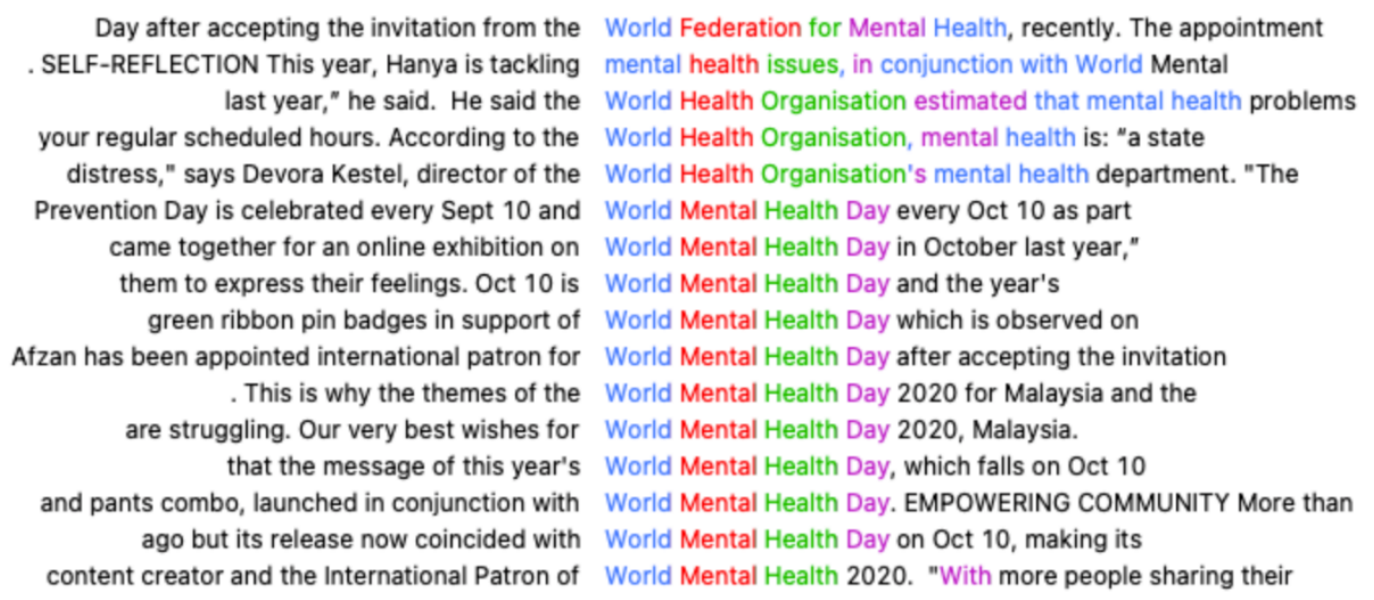

FIGURE 8. Concordance list for adjective collocate world in the New Straits Times

Example 15: ... He said the World Health Organisation estimated that mental health problems affect one in four people worldwide.

Example 16: We must try to find some normalcy in the fact that uncertainties could remain for some time. This is why the themes of the World Mental Health Day 2020 for Malaysia and the world are timely. "Let's TALK Minda Sihat", "Kesihatan Mental Milik Semua", "Bersama Cegah Bunuh Diri", "Mental Health for All" and "Greater Investment - Greater Access" all underline the spirit of solidarity and unity that we must embody.

In Example 15, the Minister of Health pointed out the escalating mental health problem in the world as reported by the World Health Organisation. In conjunction with the World Health Mental Day 2020, the themes as mentioned by the Minister of Health aptly reflected the importance of maintaining good mental health (Example 16).

\section{SEMANTIC GROUPING OF ADJECTIVES FOR SIZE}

The next semantic grouping of adjectives is size and there are two adjective collocates in this category; long and greater.

\section{CONCORDANCE LIST AND ADJECTIVE COLLOCATE FOR LONG IN THE NEW STRAITS TIMES}

The result for normalised frequency for adjective collocate long is higher in the New Straits Times than in The Star Online (see Table 6). The result for normalised frequency for the adjective collocate long in the New Straits Times is 26.7934892, while the normalised 
frequency in The Star Online is 23.0651244. The MI score is also higher in the New Straits Times (3.51033) than in The Star Online (3.18748). Figure 9 depicted the concordance list for the adjective collocate long in the New Straits Times.

Based on the concordance list from the New Straits Times (Figure 9), the adjective collocate does not literally refer to length, but to a certain length of time. It is used to describe the consequences that one needs to bear when mental health problems are ignored.

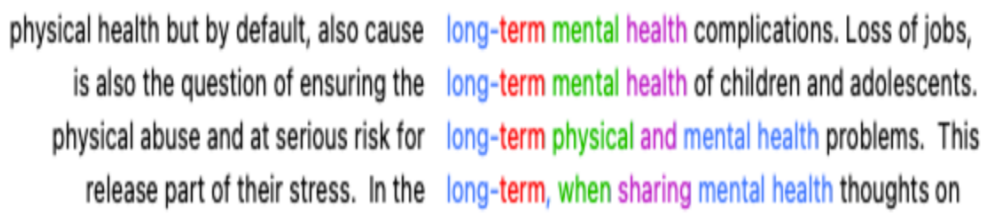

FIGURE 9. Concordance list for adjective collocate long in the New Straits Times

Examples 17 and 18 demonstrated that adjective long was used to explain the long-term consequences that an individual, including children and adolescents, has to bear when mental health problems are ignored.

Example 17: Covid-19 has shown us that it can, not only wreak havoc on physical health but by default, also cause long-term mental health complications.

Example 18: There is also the question of ensuring the long-term mental health of children and adolescents.

\section{CONCORDANCE LIST AND ADJECTIVE COLLOCATE FOR LONG IN THE STAR ONLINE}

Similar to the New Straits Times, the concordance list in Figure 10 from The Star Online suggests that adjective collocate long is also employed to depict the long-term consequence of maintaining and ensuring mental health.

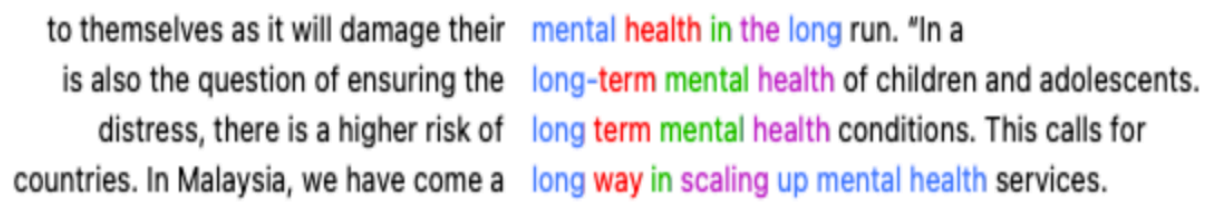

FIGURE 10. Concordance list for adjective collocate long in The Star Online

Examples 19 and 20 described how stress and emotional difficulties can turn into mental health when it is not dealt with. Anyone who need mental health related assistance are urged to seek help earlier, instead of ignoring the symptoms to avoid worsening ones' mental health state.

Example 19: If stress escalates to distress, there is a higher risk of long-term mental health conditions.

Example 20: He urged teachers not to keep emotional difficulties to themselves as it will damage their mental health in the long run. 


\section{SEMANTIC GROUPING OF ADJECTIVES FOR EVALUATIVE}

The final semantic grouping of adjectives is evaluative. There are two adjectives collocates in this category and they are health and important (Table 6). To illustrate how the adjectives were used in context in the two newspapers, the result for the adjective collocate health will be presented. The adjective collocate health obtained the highest normalised frequency among the 13 adjective collocates listed in Table 6 . The normalised frequency for health is higher in The Star Online (3690.419901) than in the New Straits Times (2391.31891). The MI score, however, is higher in the New Straits Times (7.13213) than in The Star Online (6.91192).

The concordance list (Figure 11) for health in The Star Online was associated with mental health facilities and services provided by the government, as evident in Examples 21 and 22.

\section{CONCORDANCE LIST AND ADJECTIVE COLLOCATE FOR HEALTH IN THE STAR ONLINE}

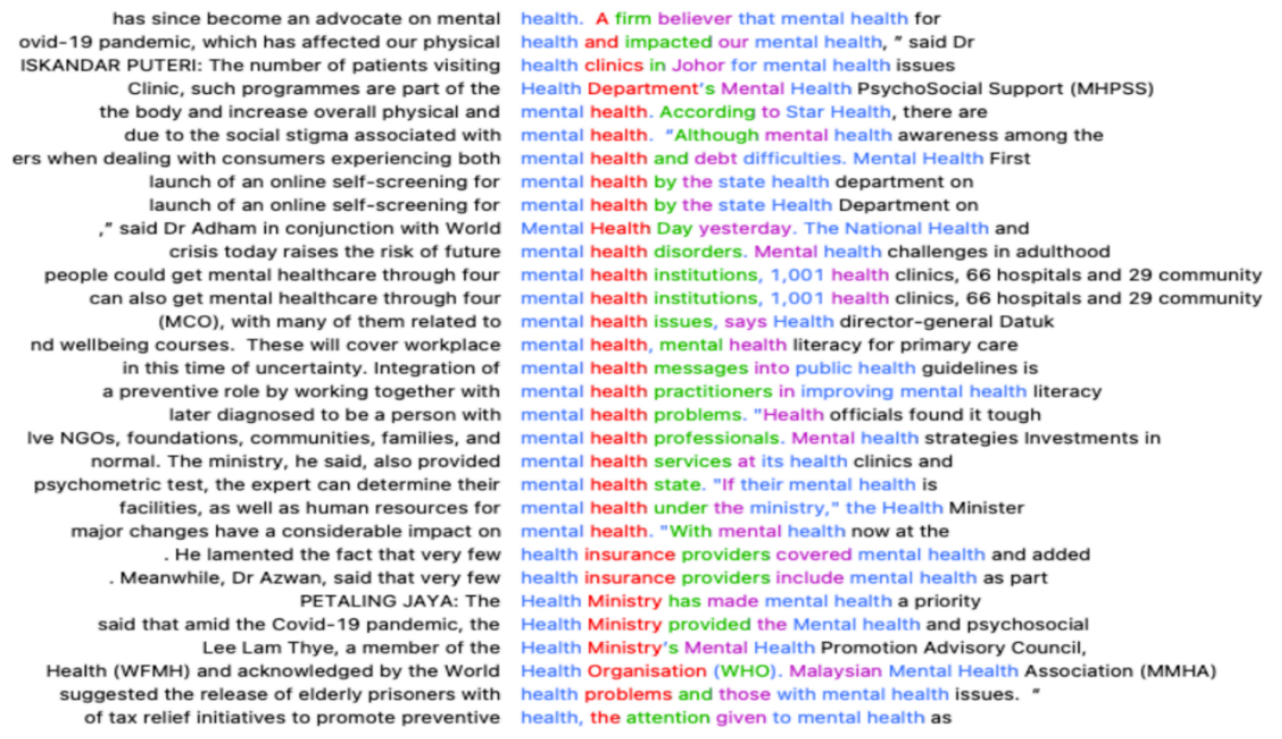

FIGURE 11. Concordance list for adjective collocate health in The Star Online

Example 21: "The people can also get mental healthcare through four mental health institutions, 1,001 health clinics, 66 hospitals and 29 community mental health centres throughout the country," said Dr Adham, congratulating Tengku Puteri Raja Tengku Puteri Iman Afzan Al-Sultan Abdullah who was recently appointed the international patron of World Mental Health Day 2020.

Example 22: Training programmes and a think-tank will be formed to anticipate and address emerging challenges and opportunities in mental health and wellbeing in the workplace and the community at large. These will cover workplace mental health, mental health literacy for primary care doctors and resources and programmes that help to develop resilience among young people in schools.

It is pertinent for the public to know that the government provides mental healthcare services and centres in Malaysia to curb mental health problems and assist those who are suffering from it (Example 21). In addition to the provision of mental health services and centres, the government realised the importance of educating people about mental health through mental health literacy programmes (Example 22). 
The concordance list for health as depicted in the New Straits Times (Figure 12), is associated with assistance that are offered to the public on mental health related issues. Reports in the New Straits Times also focused on mental health problems that occurred among the public during the Covid-19 pandemic.

\section{CONCORDANCE LIST AND ADJECTIVE COLLOCATE FOR HEALTH IN THE NEW STRAITS TIMES}

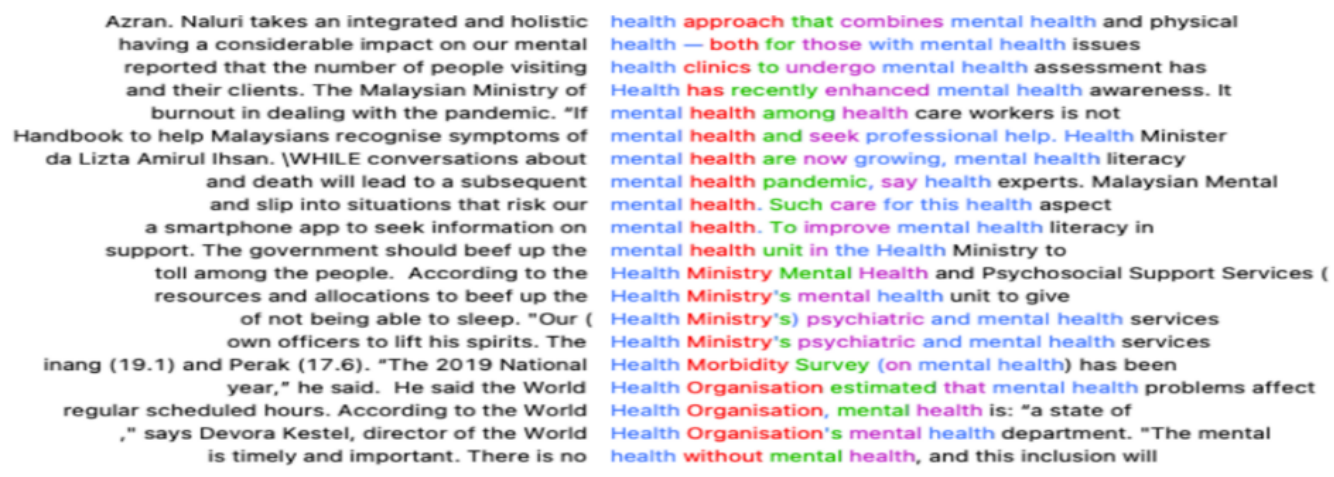

FIGURE 12. Concordance list for adjective collocate health in the New Straits Times

Example 23: According to the Health Ministry Mental Health and Psychosocial Support Services (MHPSS) report, a total of 64,366 individuals have received psychological consultation since the enforcement of the MCO until the Recovery MCO (RMCO). From the 1.6 million public workers nationwide, he said more than 15,000 employees took advantage of the counselling service as of September.

Example 24: "If mental health among health care workers is not tackled in this difficult situation, whether directly or indirectly it will negatively affect their performance, and also the pandemic. "Therefore, to minimise the effects of the Covid-19 pandemic among the general public, promotion of mental health should also be enhanced and prioritised," he said.

The Covid-19 pandemic has affected the whole world, and in Malaysia, it contributed to the rise of mental health cases. Examples 23 and 24 described the effort taken by the Malaysian government, which is setting up hotlines to support people who are struggling with the effect of the pandemic and those who have suffered from the pandemic.

\section{DISCUSSION}

The results revealed that the reports about mental health issues in the two selected Malaysian newspapers appeared to be positive. News reports in the News Straits Times and The Star are about the initiatives taken by the government to handle the issue, such as the setting up of the Malaysian Mental Health Association (MMHA), Mental Health and Psychosocial Support Services (MHPSS), mental health institutions and mental health services unit in mental health clinics and hospitals. The semantic grouping of adjectives for emotive category in both newspapers describes how pertinent it is for mental health sufferers and those who are on the verge of experiencing mental health to get support in order to maintain stable mental health. The rising cases of Covid-19 has tremendously increased the workload among medical officers, which consequently affected them mentally.

The semantic grouping of adjectives for size in both newspapers emphasises the importance of maintaining a healthy mind because when mental health problems are ignored, 
it will result in adverse long-term consequences on an individual's mental health. The Covid19 pandemic has also forced millions of people to accept the new norms of life, such as staying at home during lockdown, working from home, online teaching and learning, online meetings and other activities, which have greatly affected one's mental health (Bao et al., 2020; Nor Fariza Mohd Nor \& Adlyn Zulcafli, 2020). For the semantic grouping of adjectives for the miscellaneous category, news reports in the New Straits Times and The Star Online were on the advice given by health experts to the public regarding the importance of maintaining one's physical and mental health. The usage of the adjective collocate world which is also in the miscellaneous semantic group in the two newspapers was on the coverage of The World Mental Health day. This event is a global event which is held to support people with mental health problems and to raise awareness about this issue in order that social stigma towards people suffering from mental health problems can be reduced. The news reports in the two newspapers focus on informing the public about mental health and raising the public's awareness about mental health literacy for young people and children. This is evident in the employment of adjective collocate like health which is categorised in the semantic group of evaluative. Mental health literacy programmes must be put in place to educate the primary care givers, parents and peers who are taking care of individuals suffering from mental health problems.

Although there were reports on the number of individuals who have received psychological consultation during the MCO enforcement in Malaysia, the number of health clinics, hospitals and community health centres that are set up to assist mental health patients and sufferers, were written as factual information, instead of using negative rhetoric. The news reports in both newspapers emphasised why mental health needs to be attended to and understood by the public. The results demonstrate that the Malaysian government has taken the approach of moving away from the negative rhetoric about mental health into a positive tone of raising awareness about mental health and instilling public compassion towards individuals who suffer from mental health problems.

Overall, the findings have demonstrated that mental health related news reports examined were largely positive and contained appropriate word choice. This is a good move by the media concerned as a good mental health coverage makes understanding the illness easier (L. Gutiérrez-Coba et al., 2017). Furthermore, with such factual information and positive descriptions of mental health being presented, Malaysians hopefully would have a better understanding about the challenges and problems that mental health sufferers encounter and would be less likely to form stigmatisations of mental health (Hannaford, 2017; Woo, 2018). Consequently, mental health awareness and literacy can be developed and enhanced.

\section{CONCLUSION}

This study has explored the term mental health, and collocation analysis of adjective collocates associated with mental health in order to find out how mental health is portrayed in the newspapers, over a one year period in two online English newspapers in Malaysia. The results revealed that depictions of mental health issues in the two newspapers appeared to be positive and focused on the initiatives and activities to assist mental health sufferers. Whilst we cannot be sure whether this direction will continue, due to the limitation of this study, we can conclude that if newspaper reports focused on how to help sufferers of mental health through various assistance offered by the government and organisations before the situation turns into a state of mental illness, provide information about the challenges and problems experienced by these people and educate the public about mental health, negative perspective and stigmatisation towards mental health individual can be reduced.

Educating the public about mental health issues does not need to be done only by organising programmes, but as demonstrated, educating the public can be achieved via the 
media. However, if the media continues to report unpleasant and negative news about individuals who suffer from mental health, the public's negative perspective and stigmatisation towards individuals who suffer from mental health will continue because such reports might result in the formation of negative attitudes about mental health and may result in reinforcing the negative stereotypes. Since newspapers can shape attitudes among readers and create social representations on mental health in a certain manner (Ohlsson, 2018; Rhydderch et al., 2016), descriptions of mental health issues in the newspapers need to be monitored to decrease stigmatisation and fear towards mental health patients.

This study has its limitation in that only two newspapers were chosen as sources of data collection and data was only collected for a year, thus, suggestions for future research include increasing the number of newspapers and increasing the length of time for data collection. The corpus-driven approach can be employed with other approaches such as positive discourse analysis or critical discourse analysis to uncover the ideologies in the press about mental health issues. For researchers who are going to employ the corpus linguistics approach, it is suggested that they consider a combination of other terms such as mental depression, mental breakdown and other relevant terms. Despite its limitation, the present study has contributed to the scant literature on mental health issues in Malaysia. In addition, this study has also contributed to the research on mental health in the Asian context, since the review of literature revealed that research on mental health were mostly from the West. Furthermore, the corpus-driven approach has proven to be more systematic and rigorous than using questionnaire surveys or thematic analyses because the corpus-driven approach allows for the comparison of the language across large datasets.

\section{REFERENCES}

Ab Razak, A. (2017). Cultural construction of psychiatric illness in Malaysia. Malaysian Journal of Medical Sciences. 24(2), 1-5. https://doi.org/10.21315/mjms2017.24.2.1

Anderson, M. (2003). One flew over the psychiatric unit, mental illness and the media. Journal of Psychiatric and Mental Health Nursing. 10(3), 297-306.

Anderson, C., Robinson, E.J., Krooupa A-M. \& Henderson, C. (2018). Changes in newspaper coverage of mental illness from 2008 to 2016 in England. Epidemiology and Psychiatric Sciences. 29, e9, 1-8. https:// doi.org/10.1017/S2045796018000720.

Assaf, E. A. (2020). Hidden Power: Journalistic representations of mental health labels. In Pro Quest. Attallah College.

Azianura Hani Shaari, Marlyna Maros \& Imran Ho Abdullah. (2017). Tracking trends: The corpus analysis of lexical item jenayah in the Malaysian Hansard. Prosiding Kolokium Penerokaan Dataraya Kulturomik Malaysia, 2017, 40-45.

Bao, Y., Sun, Y., Meng, S., Shi, J., \& Lu, L. (2020). 2019-nCoV epidemic: Address mental health care to empower society. Lancet.

Bhat, D.N.S. (1994). The adjectival category: Criteria for differentiation and identification. Amsterdam/Philadelphia: Benjamins.

Biber, D., Johansson, S., Leech, G., Conrad, S. \& Finegan, E. (1999). Longman grammar of spoken and written English. Longman.

Bouillon, P. \& Viegas, E. (1999). The description of adjectives for natural language processing: Theoretical and applied perspectives. Atelier Th'ematique TALN 1999, Carg'ese, 1217 July.

Bowen, M. \& Lovell, A. (2019). Stigma: The representation of mental health in UK newspaper Twitter feeds. Journal of Mental Health. 10, 1-7. doi: 10.1080/09638237.2019.1608937

Chen, M., \& Lawrie, S. (2017). Newspaper depictions of mental and physical health. BJPsych Bulletin. 41(6), 308-313. https://doi.org/10.1192/pb.bp.116.054775 
Chong, S.T., Mohamad, M.S. \& Er, A.C. (2013). The mental health development in Malaysia: History, current issue and future development. Asian Social Science. 9(6), 1-8. https://doi.org/10.5539/ass.v9n6p1

Corrigan, P.W., Watson, A.C., Gracia, G., Slopen, N., Rasinski, K. \& Hall, L.L. (2005). Newspaper stories as measures of structural stigma. Psychiatric Services. 56(5), 551556.

Dietrich, S., Heider, D., Matschinger, H. \& Angermeyer, M.C. (2006). Influence of newspaper reporting on adolescents' attitudes toward people with mental illness. Social Psychiatry and Psychiatric Epidemiology. 41, 318-322.

Ferris, C. (1993). The meaning of syntax: A study in the adjectives of English. London/New York: Longman.

Goulden, R. \& Corker, E. \& Evans-Lacko, S., Rose, D. \& Thornicroft, G. \& Henderson, C. (2011). Newspaper coverage of mental illness in the UK, 1992-2008. BMC Public Health. 11. 796. 10.1186/1471-2458-11-796.

Hannaford, E.D. (2017). The press and public on mental health: A corpus linguistic analysis of UK newspaper coverage of mental illness (1995-2014), compared with the UK National Attitudes to Mental Illness survey. MPhil (R) Thesis, University of Glasgow. http://theses.gla.ac.uk/id/eprint/9016.

Institute of Public Health. (2015). The National Health and Morbidity Survey 2015. Ministry of Health Malaysia. 2. http://www.moh.gov.my/moh/resources/nhmsreport2015vol2.pdf

Institute for Public Health. (2019). National Health and Morbidity Survey 2019 - Technical Report. 1. http://www.iku.gov.my/nhms-2019

Jamaluddin Aziz. (2019). Exploring gender issues associated with wanita/woman and perempuan/woman in Malaysian Parliamentary Debates: A culturomic approach, GEMA Online ${ }^{\circledR}$ Journal of Language Studies. 19(4), 278-301. http://doi.org/10.17576/gema-2019-1904-15

Kennedy, C. (2006). Vagueness and grammar: The semantics of relative and absolute gradable adjectives. Linguist Philos. Springer. https://doi.org/10.1007/s10988-006-9008-0

Klin, A. \& Lemish, D. (2008). Mental disorders stigma in the media: review of studies on production, content, and influences. Journal of Health Communication. 13(5), 434-449. https://doi.org/10.1080/10810730802198813

L. Gutiérrez-Coba, A. Salgado-Cardona, V. García Perdomo, Y. Guzmán- Rossini. (2017): Coverage of mental health in the Colombian Press, an ongoing contribution. Revista Latina de Comunicación Social. 72, 114-128. http://www.revistalatinacs.org/072paper/1156/06en.html. DOI: 10.4185/RLCS-20171156

Lazard, A., Scheinfeld, E., Bernhaardt, J.M., Wilcox, G.B. \& Suran, M. (2015). Detecting themes of public concern: A text mining analysis of the centers for disease control and prevention's Ebola live twitter chat. American Journal of Infection Control. 43(10), 1109-1111. doi: 10.1016/j.ajic.2015.05.025

Lim, S. L. (2018). Bridging barriers: A report on improving access to mental healthcare in Malaysia. Penang Institute, January, 1-141. https://penanginstitute.org/programmes/penang-institute-in-kuala-lumpur/1032bridging-barriers-a-study-on-improving-access-to-mental-healthcare-in-malaysia/

McLean. Harvard Medical School Affiliate. (n.d.) Yes, there is a big difference between mental health and mental illness. https://www.mcleanhospital.org/essential/yes-there-bigdifference-between-mental-health-and-mental-illness. Retrieved on $20^{\text {th }}$ March, 2021.

Medical Developmental Vision Ministry of Health Malaysia. (2011). Psychiatric and Mental Health Services Operational Policy.

Mental Health Foundation. (2015). Fundamental facts about mental health 2015. Mental Health 
Foundation: London, 1-94. https://doi.org/10.1090/gsm/088/01

Mental Health Foundation. (2016) Fundamental facts about mental health 2016. Mental Health Foundation: London, 1-89. https://www.mentalhealth.org.uk/sites/default/files/fundamental-facts-about-mentalhealth-2016.pdf

Newman, N., Richard Fletcher, W., Schulz, A., And1, S. \& Kleis Nielsen, R. (2020). Reuters Institute Digital News Report 2020.

Nor Fariza Mohd Nor, Anis Nadiah Che Abdul Rahman, Azhar Jaluddin, Imran Ho Abdullah \& Sabrina Tiun. (2019). A corpus driven analysis of representations around the word 'ekonomi' in Malaysian Hansard Corpus. GEMA Online Journal of Language Studies. 19(4), 66-95. http://doi.org/10.17576/gema-2019-1904-04

Nor Fariza Mohd Nor \& Adlyn Syahirah Zulcafli. (2020). Corpus driven analysis of news reports about Covid-19 in a Malaysian online newspaper. GEMA Online Journal of Language Studies. 20(3), 199-220. http://doi.org/10.17576/gema-2020-2003-12

Norsimah, M.A, Azhar, J., Anis Nadiah, C.A.R. \& Imran, H.A. (2019). "Is Selangor in deep water?": A Corpus-driven account of air/water in the Malaysian Hansard Corpus (MHC). GEMA Online ${ }^{\circledR}$ Journal of Language Studies. 19(2), 99-120. http://doi.org/10.17576/gema-2019-1902-07

Nunnally, J. (1957). The communication of mental health information: A comparison of the opinions of experts and the public with mass media presentations. Behavioral Science. 2(3), 222-230. https://doi.org/10.1002/bs.3830020305

Oakes, M.P. (1998). Statistics for corpus linguistics. Edinburgh University Press.

Ohlsson, R. (2018). Public discourse on mental health and psychiatry: Representations in Swedish newspapers. Health (United Kingdom), 1-17. https://doi.org/10.1177/1363459317693405

Our World in Data. (2018). https://www.singlecare.com/blog/news/mental-health-statistics/

Pirkis, J., Blood, R.W., Francis, C. \& MacCallum, K. (2006). On-screen portrayals of mental illness: Extent, nature, and impacts. J Health Commun. 11(5), 523-541.

Pirkis J, Francis C. (2012). Mental illness in the news and the information media: A critical review. Canberra: Commonwealth of Australia.

Price, H. (2019). The discursive construction of mental illness in UK newspapers (1984-2014): A Critical Corpus Linguistic Analysis. University of Huddersfield.

Razali, Z.A., Sanip, S. \& Sa'Ad, R.A. (2018). Mental illness potrayal in media: A summative content analysis of Malaysian newspapers. International Journal of Business and Society. 19(S2), 324-331.

Rhydderch, D., Krooupa, A. M., Shefer, G., Goulden, R., Williams, P., Thornicroft, A., Rose, D., Thornicroft, G. \& Henderson, C. (2016). Changes in newspaper coverage of mental illness from 2008 to 2014 in England. Acta Psychiatrica Scandinavica. 134, 45-52. https://doi.org/10.1111/acps. 12606

Roth, D. (2004). Mass media and mental illness: A literature review. Ontario: Mental Health Association.

Sinclair, J. (Ed.). (1991). Corpus, concordance, collocation. Oxford, UK: Oxford University Press.

Slopen, N.B., Watson, A.C., Gracia, G. \& Corrigan, P.W. (2007). Age analysis of newspaper coverage of mental illness. Journal of Health Communication. 12(1), 3-15. https://doi.org/10.1080/10810730601091292

Storjohann, P. (2005). Corpus-driven vs. corpus-based approach to the study of relational patterns. Proceedings of the Corpus Linguistics Conference, 1-20. http://www.elexiko.de

The Star Online. (2019, October 17). Examining the stigma of mental health illness in Malaysia. 
https://www.thestar.com.my/lifestyle/health/2019/10/17/stigma-of-mental-illness

Thorton, J.A. \& Wahl, O. (2006). Impact of a newspaper article on attitudes toward mental illness. Journal of Community Psychol. 24(1), 17-25.

Tobin, G. \& Lyddy, F. (2014). Media representation of depression in young people: A corpusbased analysis of Irish newspaper coverage. Irish Journal of Psychological Medicine. 31(1), 21-30. https://doi.org/10.1017/ipm.2013.64

Walter, M. (2015). Language effects on mental health stigma. Washburn University.

Whitley, R. (2018). Media coverage on mental illness. Visions. 14(1), 37.

Woo, A. (2018). Junkie, addict or person with a substance use disorder? Language in Journalism. Visions. 4(1), 35-37.

World Health Organization. (2004). Promoting mental health. In World Health Organization. https://doi.org/10.5840/ncbq201616462

World Health Organization. (2019a). The WHO special initiative for mental health (20192023): Universal health coverage for mental health.

World Health Organization. (2019b). The WHO special initiative for mental health (20192023): Universal health coverage for mental health. World Health Organization, 1-4. https://apps.who.int/iris/bitstream/handle/10665/310981/WHO-MSD-19.1eng.pdf?ua $=1$

Xiao, R., \& McEnery, T. (2006). Collocation, semantic prosody, and near synonymy: A crosslnguistic perspective. Applied Linguistics. 27(1), 103-129. https://doi.org/10.1093/applin/ami045

\section{ABOUT THE AUTHORS}

Nor Fariza Mohd Nor (Ph.D.) is an Associate Professor at the Centre for Research in Language and Linguistics, Faculty of Social Sciences and Humanities, Universiti Kebangsaan Malaysia (UKM). Her area of interests are critical discourse analysis, corpus linguistics and digital humanities. She is currently the Chair of the Centre for Research in Language and Linguistics.

Novelia Bernice Jeffree has a Bachelor of Education (Honours) in Teaching English as a Second Language (TESL) from UKM's Faculty of Education. She is currently pursuing her MA in English Language Studies at the Centre for Research in Language and Linguistics, UKM.

Hilwa Abdullah @ Mohd. Nor (Ph.D.) is currently a lecturer and clinical psychologist at the Centre for Psychology and Human Well-being, Faculty of Social Sciences and Humanities, UKM. Hilwa specialises in clinical psychology specifically in mental health and psychology of child and adolescents. Her research focuses on the causes, prevalence, assessment, diagnosis and treatment for various mental disorders. 